\title{
Use of healthcare services and therapeutic measures associated with new episodes of acute low back pain- related disability among elderly people: a cross-sectional study on the Back Complaints in the Elders - Brazil cohort
}

\author{
Juleimar Soares Coelho de Amorim', Vitor Tigre Martins Rocha", Lygia Paccini Lustosa"', Leani Souza Máximo Pereira"V \\ Physical Education, Physical Therapy and Occupational Therapy School, Universidade Federal de Minas Gerais (UFMG), Belo Horizonte (MG), Brazil
}

PhD. Physiotherapist and Associate Professor, Physical Therapy Course, Instituto Federal de Educação Ciência e Tecnologia do Rio de Janeiro (IFRJ), Rio de Janeiro (RJ), Brazil.

(D) https://orcid.org/0000-0003-3218-1769

"MD. Physiotherapist, Postgraduate Program on Rehabilitation Sciences, Department of Physical Therapy, Universidade Federal de Minas Gerais (UFMG), Belo Horizonte (MG), Brazil.

(D) https://orcid.org/0000-0002-5789-0820

"'PhD. Physiotherapist and Associate Professor, Postgraduate Program on Rehabilitation Sciences, Department of Physical Therapy, Universidade Federal de Minas Gerais (UFMG), Belo Horizonte (MG), Brazil.

(D) https://orcid.org/0000-0002-0919-1320

"vphD. Physiotherapist and Associate Professor, Postgraduate Program on Rehabilitation Sciences, Department of Physical Therapy, Universidade Federal de Minas Gerais (UFMG), Belo Horizonte (MG), Brazil.

(D) https://orcid.org/0000-0001-7253-4392

KEY WORDS (MeSH terms):

Low back pain.

International Classification of Functioning,

Disability and Health.

Disability studies.

Health services for the aged.

\section{AUTHORS' KEY WORDS:}

Elders.

Disability.

Disability-related low back pain

Doctor visits.

Crowding-in effects.

\begin{abstract}
BACKGROUND: Patients with low back pain frequently undergo a variety of diagnostic and therapeutic interventions, but some of these have uncertain effectiveness. This highlights the importance of the association of healthcare services and therapeutic measures relating to disability.

OBJECTIVE: To analyze the use of healthcare services and therapeutic measures among Brazilian older adults with disability-related low back pain.

DESIGN AND SETTING: Observational cross-sectional study on baseline assessment data from the Back Complaints in the Elders - Brazil (BACE-B) cohort.

METHODS: The main analyses were based on a consecutive sample of 602 older adult participants in BACE-B (60 years of age and over). The main outcome measurement for disability-related low back pain was defined as a score of 14 points or more in the Roland Morris Questionnaire.

RESULTS: Visits to doctors in the previous six weeks (odds ratio, $\mathrm{OR}=1.82 ; 95 \%$ confidence interval, $\mathrm{Cl}$ 1.22-2.71) and use of analgesics in the previous three months $(\mathrm{OR}=1.57 ; 95 \% \mathrm{Cl} 1.07-2.31)$ showed statistically significant associations with disability-related low back pain. The probability of disability-related low back pain had an additive effect to the combination of use of healthcare services and therapeutic measures $(O R=2.57 ; 95 \%$ Cl 1.52-4.36). The analyses showed that this association was significant among women, but not among men. CONCLUSIONS: Occurrence of the combined of consultations and medication use was correlated with higher chance of severe disability among these elderly people with nonspecific low back pain. This suggested that overuse and "crowding-in" effects were present in medical services for elderly people.
\end{abstract}

\section{INTRODUCTION}

Disabilities caused by chronic-degenerative diseases and their symptoms, such as spinal problems, combined with the aging population, are a major challenge to healthcare systems around the world. ${ }^{1,2}$ Low back pain is the single biggest cause of years lived with disability worldwide and is the condition that most contributes to overall disability and life years with disability. ${ }^{3,4}$

In Brazil's National Household Sampling Survey (Pesquisa Nacional por Amostra de Domicílio), performed in 2003, back pain was identified as the most prevalent chronic disease. Its incidence increased with increasing age, to reach $40 \%$ among older adults between 69 and 79 years of age. ${ }^{5}$ The point-prevalence of low back pain was found to be $25.0 \%$ among elderly Brazilians in a systematic review, and other studies indicated its potential to affect the functions, activities and social participation of older adults, with concomitant impacts on quality of life and independence. ${ }^{4,6-8}$

Longitudinal analyses have shown that after one year, $60.3 \%$ of older adults with low back pain continue to present disability. After two years, the disability-related low back pain of only $36 \%$ of older adults has halved, which demonstrates the long-term latency of such complaints. ${ }^{9,10}$ It has consequently been observed that the high prevalence of low back pain, its related disability and the poor long-term prognosis induces older adults to request specific interventions. ${ }^{11}$ Among community-dwelling elderly people, about $58 \%$ seek healthcare due to low back pain. ${ }^{12}$ Patients with back pain frequently undergo a variety of diagnostic and therapeutic interventions (imaging tests, injections, pain medications, physical therapy, surgery, braces, etc.), and some of these have uncertain effectiveness. ${ }^{13-17}$ Elderly people with severe disability have been found to 
be 3.8 times more likely to be seeking care, and factors like gender, histories of previous low back pain and general health also influence care-seeking behavior. ${ }^{12}$

Recent reports have shown that people with the poorest physical and mental health are significantly more likely to present associated low back pain-related disability. ${ }^{18,19}$ The causes of use of healthcare services and therapeutic measures are related to context (types of healthcare systems and their organization, for example) and individual factors (age, sex, education and income). ${ }^{20,21}$ According to the classical model of Andersen and Newman, individual factors include predisposing factors (age and sex), ${ }^{21}$ enabling characteristics (like education level and income) and healthcare needs from the perspectives of professionals and users. Thus, the findings from the existing studies cannot be extrapolated to populations in low and middle-income countries, such as Brazil, due to differences in the setup and planning of their healthcare systems.

Studies on the utilization of healthcare services and therapeutic measures among older adults with disability-related low back pain remain at an initial stage. Therefore, it was sought through the present study to investigate the healthcare services and therapeutic measures that are used in relation to complaints of acute low back pain-related disability among community-dwelling elderly people. We hypothesized that the associations between the characteristics of use of healthcare and therapeutic measures and occurrences of disability would differ between the sexes.

\section{OBJECTIVE}

In this study, data from the Back Complaints in the Elders - Brazil (BACE-B) cohort were used. The aim was to analyze associations between the use of healthcare services and therapeutic measures and occurrences of disability reported by elderly people.

\section{METHODS}

\section{Study design and ethics}

This study forms part of an international consortium of epidemiological studies named Back Complaints in the Elders, which includes researchers in Australia, Brazil and the Netherlands. ${ }^{22}$ The Back Complaints in the Elders - Brazil project is a prospective cohort study with data collected between October 2011 and September 2015. The present analysis was an observational cross-sectional study on baseline assessment data from the Back Complaints in the Elders - Brazil cohort. Ethical approval for this study was obtained from the Ethics Committee of the Federal University of Minas Gerais (Universidade Federal de Minas Gerais, UFMG), under the number ETIC 0100.0.203.000-11, on February 24, 2016.

\section{Study population}

The sample for this study comprised consecutive participants in the baseline survey for the Back Complaints in the Elders - Brazil cohort. They were aged $\geq 60$ years, with acute complaints of low back pain, and were residents in the metropolitan region of Belo Horizonte, Minas Gerais, Brazil. Elderly people with low back pain symptoms were identified by healthcare professionals (physicians, physiotherapists and occupational therapists, among others) working in either the public or the private healthcare sector, and were directed to the BACE-B research team.

Only elderly people presenting criteria for a new episode of acute low back pain were included in the Back Complaints in the Elders - Brazil study. Low back pain was defined as complaints of pain, tension or stiffness in the region between the last ribs and the gluteal line, with or without irradiation of pain to the lower limbs. ${ }^{23}$ A new episode of low back pain was defined as a situation in which the individual had not sought treatment for low back pain over a sixmonth period immediately preceding participation in the study. ${ }^{22}$ Acute symptoms were defined as an occurrence of a low back pain crisis not more than six weeks before the baseline assessment. ${ }^{24}$

Participants with visual, motor, hearing or cognitive impairment that could influence their responses to questionnaires or prevent adequate performance in physical and functional tests were excluded. ${ }^{25}$

\section{Outcome variable}

The outcome measurement of this study was disability-related low back pain, as assessed using the Roland Morris Disability Questionnaire (RMDQ), which consists of 24 items relating to the influence of back pain on daily activities and measures the level of disability associated with low back pain. The questionnaire scores range from 0 to 24 , with higher scores indicating a worse level of disability. ${ }^{26,27}$ Scores over 14 were taken to indicate severe disability. ${ }^{27}$

\section{Exposure variable}

Five indicators of use of healthcare services were considered: doctor visits made over the preceding six weeks, including generalist, specialist and occupational doctors; physiotherapy consultations over the preceding six weeks; diagnostic tests made during the preceding three months, including blood tests, $\mathrm{X}$-rays, computed tomography and magnetic resonance imaging; and use of analgesics and complementary noninvasive therapies (orthoses, braces, acupuncture, yoga, Pilates, overall postural re-education or other types).

\section{Sociodemographic and back pain variables}

Potential confounding variables were selected for this analysis based on the theoretical model of Andersen and Newman, ${ }^{21}$ in 
which predisposing and enabling factors for the use of healthcare services were considered. Among the predisposing factors, sex and age (continuous variable) were considered. Among the enabling factors, living with a spouse/partner (yes or no), educational level/schooling years (less than four; or four or more) and own income (up to one minimum monthly wage, two to four, or five or more) were considered.

The low back pain intensity in the last week was evaluated by means of a numerical rating scale (NRS), on which the scores could range from 0 (no pain) to 10 (maximum pain).

\section{Statistical analysis}

Descriptive analyses were performed on the outcomes investigated, both for the total population and with stratification according to sex, using proportions and means (with standard deviation). Comparisons between groups were made using Pearson's chi-square or Fisher's exact test (for proportions), or using Student's t test (for means).

Multivariate analysis was done to investigate associations between disability and indicators of use of healthcare services and therapeutic measures and was based on odds ratio (OR) estimates, by means of binary logistic regression. The multivariate models were adjusted for age, sex, living with spouse/partner, education level and income. Binary logistic regression was used to estimate the predicted probability of occurrences of doctor visits over the preceding six weeks and use of analgesic medications over the preceding three months, according to disability.

All the analyses were performed using the procedures for complex samples in the Stata statistical package, version 13.0 (StataCorp LLC, College Station, TX, United States), with a significance level of $5 \%$.

\section{RESULTS}

The sample consisted of 602 elderly people with complaints of acute nonspecific low back pain. Figure 1 illustrates the selection process for the participants in this study.

The participants' mean age was $67.7 \pm 7.0$ years. They were mostly female (84.9\%), with an education level of more than four years of schooling (38.5\%) and had low income (86.5\% had a mean income of not more than four minimum monthly wages). Their mean pain intensity was $7.2( \pm 2.6)$ on the numerical rating scale. The prevalence of severe low back pain-related disability was $54.5 \%$ (95\% CI 50.5-58.4) for all participants, 54.6\% (95\% CI 50.2-58.9) for woman and $53.8 \%$ (95\% CI 43.4-64.0) for men. The prevalence of disability was significantly higher among the elderly people with higher education level: $54.7 \%$ in the sample overall; $56.8 \%$ among the women, but $42.9 \%$ among the men. More details on the sociodemographic characteristics of the survey participants can be seen in Table 1.
Table 2 presents the characteristics of usage of healthcare services and therapeutic measures among all the participants and stratified according to sex and disability. Just $3.0 \%$ of these elderly people had consulted a physical therapist during the preceding six weeks, while $74.1 \%$ had used at least one analgesic. The results from bivariate analysis on the association between disability and indicators of use of healthcare services showed that the proportion of disability was more significant among those who had visited doctors during the preceding six weeks (35.4\%), but not for men alone (30.6\%). Among the indicators of therapeutic measures, the proportion of disability was higher among the elderly people who had used analgesics (78.1\%) and was even higher among the women $(79.9 \%)$.

Table 3 shows odds ratios for indicators of use of healthcare services and therapeutic measures due to low back pain-related disability for the total sample, adjusted for sociodemographic characteristic. The elderly people who visited doctors were 1.82 times (95\% CI 1.22-2.71) more likely to present severe disability. The subjects who used analgesics were 1.57 times (95\% CI 1.07$2.31)$ more likely to present disability. Women who visited doctors and used analgesics were significantly more likely to present severe disability. However, no significant association was found between the indicators of use of healthcare services and therapeutic measures and occurrences of severe disability in men. An additive effect was observed with regard to the chances of disability, in analyzing the combination of doctor visits and use of analgesics, both for the total sample $(\mathrm{OR}=2.57$; $95 \%$ CI 1.52-4.36) and for women $(\mathrm{OR}=2.80$; 95\% CI 1.58-4.94).

Figure 2 shows that the predicted probability of doctor visits and use of analgesics was clearly stratified between different ages, with more significant probability among elderly people with severe disability.

\section{DISCUSSION}

The results from this study showed that among elderly people, low back pain-related severe disability was associated with more significant chances of going to visit a doctor and using analgesics, even after taking into account potential confounding factors. Nevertheless, it should be noted this was more evident among women.

Doctor visits are a positive aspect of healthcare, since they provide opportunities for timely diagnosis, prevention, treatment and referral for rehabilitation. ${ }^{19}$ Perception of the severity of pain and, consequently, disability, may form the trigger for seeking medical attention. ${ }^{28,29}$ On the other hand, we expected that the elderly people who sought medical care and made use of analgesic medication would achieve relief from their pain symptoms and subsequently from the resulting disability. However, senescence and senility can cause higher demand for medical appointments, not 
Older adults with complaints of low back pain

Reasons for exclusion $(n=2,796)$

I- Age $<60$ years $(n=377)$

II - Without new episode of acute low back pain $(n=1,770)$

III - Severe visual/ hearing impairments $(n=12)$

IV - Severe motor impairments $(n=5)$

$V-\geq 2$ reasons for exclusion $(n=123)$

$\mathrm{VI}$ - Refused to participate $(\mathrm{n}=264)$

VII - Other reasons $(n=169)$

VIII - Missing $(n=76)$

Participants included in this study $(n=602)$

Figure 1. Flowchart of entry of participants into the study.

Table 1. Sociodemographic and pain intensity characteristics of the sample of older adults complaining of acute low back pain, according to presence of disability, and with stratify according to sex. Back Complaints in the Elders - Brazil, 2016

\begin{tabular}{|c|c|c|c|c|c|c|c|c|c|c|}
\hline \multirow[b]{3}{*}{ Characteristic } & \multirow{3}{*}{$\begin{array}{c}\text { Total } \\
\text { sample } \\
(n=602)\end{array}$} & \multicolumn{9}{|c|}{ Disability* } \\
\hline & & \multicolumn{2}{|c|}{ All participants } & \multirow[b]{2}{*}{ P-value } & \multirow{2}{*}{$\begin{array}{l}\text { Women } \\
\text { Not severe } \\
(38.5 \% \text {; } \\
=232)\end{array}$} & \multirow[b]{2}{*}{$\begin{array}{l}\text { Severe } \\
(46.3 \% ; n \\
=279)\end{array}$} & \multirow[b]{2}{*}{ P-value } & \multirow{2}{*}{$\begin{array}{c}\text { Men } \\
\text { Not severe } \\
(7.0 \% ; n= \\
42)\end{array}$} & \multirow[b]{2}{*}{$\begin{array}{c}\text { Severe } \\
(8.1 \% ; n= \\
49)\end{array}$} & \multirow[b]{2}{*}{ P-value } \\
\hline & & $\begin{array}{l}\text { Not severe } \\
(45.5 \% ; \mathrm{n} \\
\quad=274)\end{array}$ & $\begin{array}{l}\text { Severe } \\
\begin{array}{l}(54.5 \% ; n \\
=328)\end{array}\end{array}$ & & & & & & & \\
\hline Age, median (SD) & $67.7(7.0)$ & $68.1(6.9)$ & $67.3(7.1)$ & 0.157 & $67.9(6.6)$ & $67.5(7.2)$ & 0.483 & $69.4(8.4)$ & $66.4(6.5)$ & 0.060 \\
\hline \multicolumn{11}{|l|}{ Living, \% } \\
\hline \multicolumn{11}{|l|}{ Education level, \% } \\
\hline$<4$ years & 38.5 & 30.3 & 45.3 & \multirow{2}{*}{$<0.001$} & 30.4 & 43.2 & \multirow{2}{*}{0.003} & 29.3 & 57.1 & \multirow{2}{*}{0.008} \\
\hline 4 or more years & 61.5 & 69.7 & 54.7 & & 69.6 & 56.8 & & 70.7 & 42.9 & \\
\hline \multicolumn{11}{|c|}{ Income in minimum monthly wages, $\%$} \\
\hline Up to 1 & 39.7 & 34.7 & 44.0 & 0.070 & 35.1 & 45.3 & 0.061 & 32.5 & 36.2 & 0.806 \\
\hline
\end{tabular}

"Low back pain-related disability assessed using the Roland Morris Disability Questionnaire (RMDQ); SD = standard deviation; NRS = numerical rating scale. 
Table 2. Bivariate analysis on the association between disability, indicators of use of healthcare services and indicators of therapeutic measures in the sample of older adults aged 60 years or over with complaints of acute low back pain. Back Complaints in the Elders - Brazil, 2016

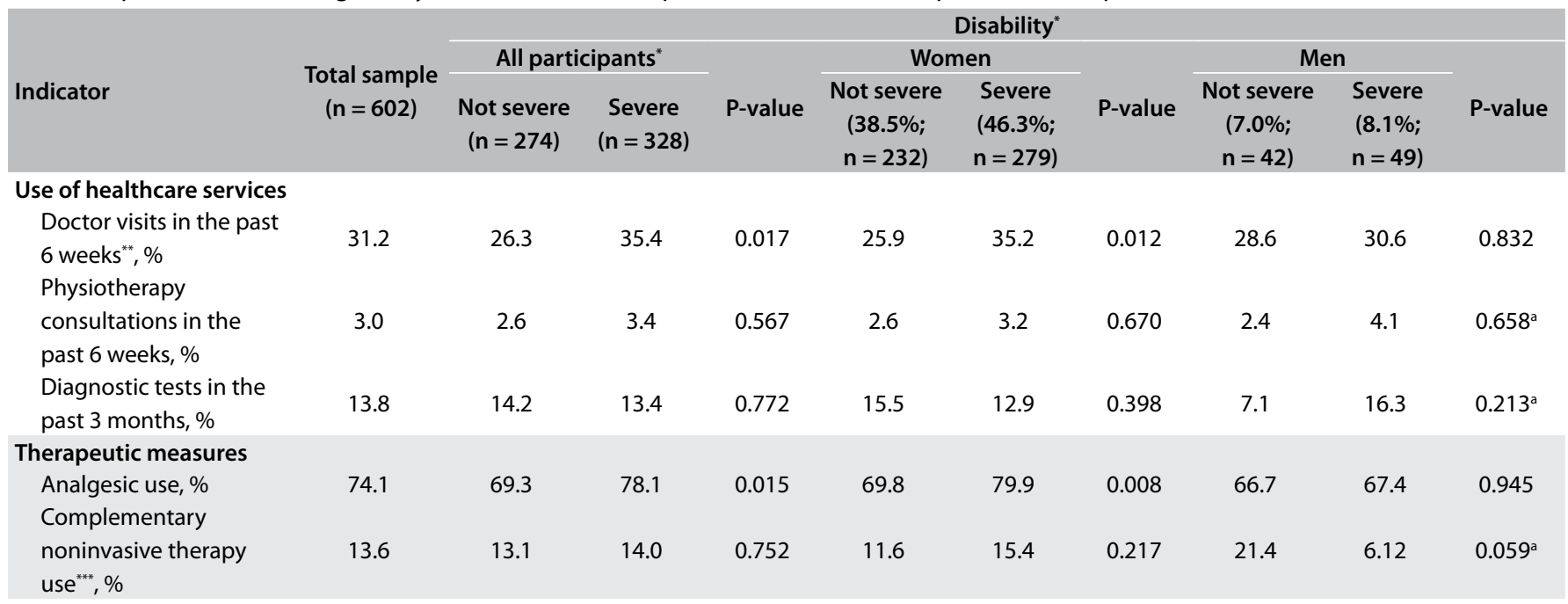

"Low back pain-related disability assessed using the Roland Morris Disability Questionnaire (RMDQ); *Doctor visits included general practitioner, specialist and occupational doctors; ${ }^{* * *}$ Complementary noninvasive therapies included use of orthoses, braces, acupuncture, yoga, Pilates, overall postural re-education or

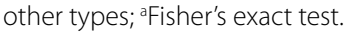

Table 3. Multivariate logistic regression between indicators of use of healthcare services and therapeutic measures and occurrences of disability among older adults with complaints of acute low back pain. Back Complaints in the Elders - Brazil, 2016

\begin{tabular}{|c|c|c|c|c|c|c|}
\hline \multirow{2}{*}{ Indicator } & \multicolumn{2}{|c|}{ All participants* } & \multicolumn{2}{|c|}{ Women* } & \multicolumn{2}{|c|}{ Men $^{*}$} \\
\hline & OR $(95 \% \mathrm{Cl})$ & P-value & OR $(95 \% \mathrm{Cl})$ & P-value & OR $(95 \% \mathrm{Cl})$ & P-value \\
\hline Physiotherapy consultations in the past 6 weeks & $1.07(0.38-2.96)$ & 0.902 & $0.97(0.32-2.94)$ & 0.963 & $2.82(0.17-47.32)$ & 0.472 \\
\hline Analgesic use & $1.57(1.07-2.31)$ & 0.021 & $1.64(1.08-2.50)$ & 0.021 & $1.07(0.36-3.16)$ & 0.908 \\
\hline Complementary noninvasive therapy use ${ }^{* * *}$ & $1.27(0.76-2.11)$ & 0.361 & $1.60(0.92-2.77)$ & 0.094 & $0.26(0.05-1.39)$ & 0.115 \\
\hline
\end{tabular}

$\mathrm{OR}=$ odds ratio; $\mathrm{Cl}=$ confidence interval; ${ }^{*}$ Odds ratio and $95 \%$ confidence interval adjusted for age, living with spouse or partner, education level, income and pain intensity, as estimated through logistic regression; the exposure category was the low back pain-related disability and the response variables were the indicators of use of healthcare services and therapeutic measures; * Doctor visits included general practitioner, specialist and occupational doctors;

${ }^{* * *}$ Complementary noninvasive therapies included use of orthoses, braces, acupuncture, yoga, Pilates, overall postural re-education or other types.
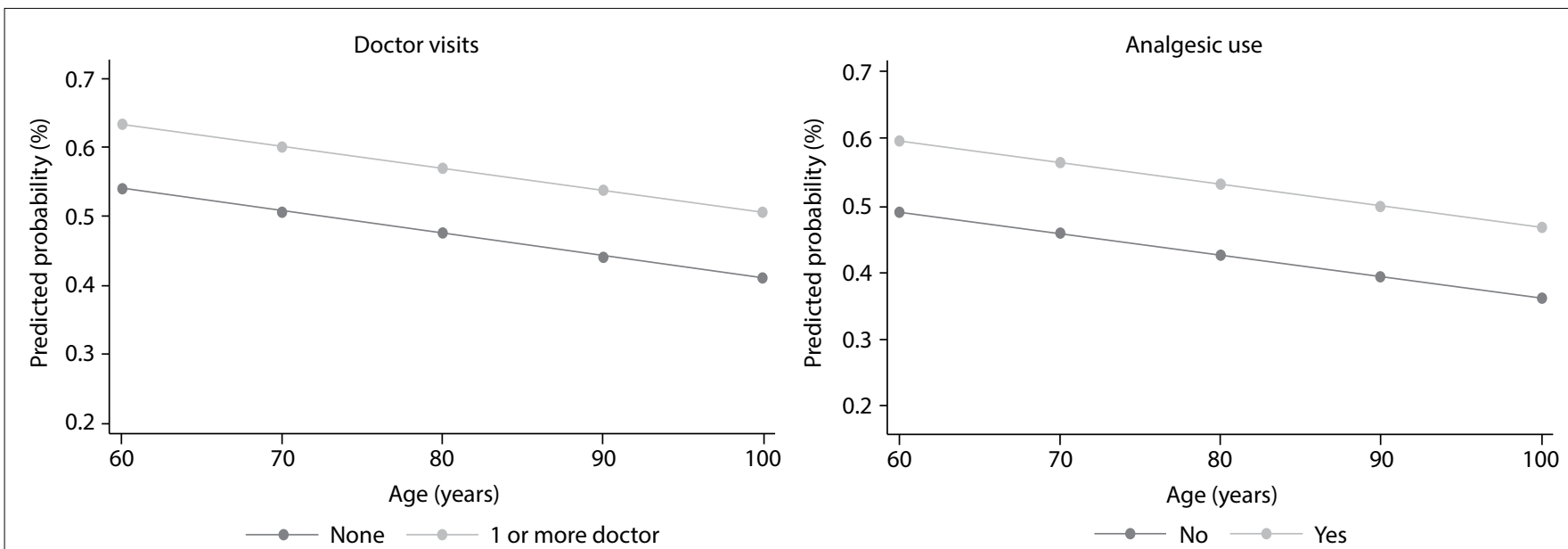

"Model adjusted for age, living with spouse or partner, education level and income, as estimated using logistic regression." Low back pain-related disability assessed using the Roland Morris Disability Questionnaire (RMDQ).

Figure 2. Predicted probability* of visits to one or more doctor in the past six weeks and use of analgesics in the past three months, along the age continuum, according to disability**. Back Complaints in the Elders - Brazil, 2016. 
only because of associations between pains and/or disability, but also because of involvement of the psycho-affective profile inherent to this age group. Among elderly people, stress, anxiety and depression are manifestations linked to occurrences of nonspecific low back pain and seeking medical appointments. ${ }^{30,31}$ Another reason for the more extensive use of healthcare services among elderly people with disabilities is their higher prevalence of chronic diseases and comorbidities, along with their complications, which lead to increased use of medications. ${ }^{17,32}$ Occurrences of psycho-affective factors and polypharmacy or other health conditions among elderly people can obscure accurate definition of the legitimate causal mechanisms that trigger severe symptoms of low back pain. This, which gives rise to a complex multidirectional relationship, means that it is sometimes impossible to distinguish temporal relationships from each manifestation, its diagnosis and the appropriate therapeutic approach. ${ }^{33}$ In addition, the overuse of healthcare services by elderly people has been shown to be a marker of care with only moderate resolution. Because of the complex nature of painful dysfunction, many elderly people are discharged from specialized rehabilitation services without any resolution for their pain symptoms and, thus, they continue to present disabilities. ${ }^{34}$

Medicines are widely prescribed at the beginning of the course of low back pain, although there is no consensus regarding recommendations for their use among elderly people. ${ }^{11,35,36}$ Our results have added to those in the literature, through understanding that inadequate management of healthcare can cause greater disabilities. The first line drugs recommended in the literature for reducing pain are analgesics and nonsteroidal anti-inflammatory drugs (NSAIDs). ${ }^{37,38}$ Nonetheless, even these drugs can result in side effects in elderly people. Their effectiveness remains unproven in relation to low back pain, compared with exercise, for example. ${ }^{39}$ Corroborating our results, increased risk of disability through chronic use of opioids within healthcare has been shown in the literature ${ }^{40,41}$ Elderly people are more susceptible to the adverse effects of opioids, as has been shown through associations with falls and fractures, ${ }^{42}$ worse health outcomes, including worsening pain, ${ }^{43}$ increased likelihood of surgery and drug addiction after using painkillers for up to two years. ${ }^{41,43}$ Especially in older adults, important side effects associated with opioid use have been reported, including higher hospitalization risks, cardiovascular events, instability and cognitive impairment. ${ }^{44-46}$ Furthermore, common adverse effects such as bowel dysfunction, constipation, nausea and somnolence can put older adults at risk of injuries and losses of daily function. ${ }^{47}$

Our results showed that elderly users of analgesics were 1.57 times more likely to present low back pain-related disability. Furthermore, the combination analysis on medical consultations and analgesics demonstrated that these individuals presented 2.57 times higher chance of disability. Gold et al. ${ }^{48}$ demonstrated that elderly people with low back pain who received opioid medication early were 1.6 times more likely to have a new medical consultation and greater low back pain-related disability. Overuse of interventions and a "crowding-in effect", defined as an additive combination of therapeutic and diagnostic measures, ${ }^{49}$ occur frequently among elderly people with low back pain..$^{29}$ However, a more thorough understanding of perceived needs is necessary, to ensure effective results for patients and for the healthcare system. In a study on the use of healthcare services among 4,814 Italian elderly people, home and specialized care were used twice as often among those with disabilities. ${ }^{49}$ Chou et al. ${ }^{14}$ demonstrated that patients with nonspecific low back pain sought medical care in order to obtain a diagnosis and receive treatment options, but that they only showed concerns relating to pharmacotherapy. In the same study, the authors concluded that, so far, both non-pharmacological and pharmacological interventions have only been seen to have low to moderate effects in treatments for low back pain. Therefore, these issues need to be considered in developing approaches toward managing low back pain, to minimize negative effects like disability among elderly people.

Greater severity of disability was observed among women. In analyzing the associations with the interventions used, the results indicated that this stratification existed in relation both to doctor visits and to analgesic use. This hypothesis was confirmed in previous studies that demonstrated greater disability and worse prognosis for nonspecific low back pain among elderly women. ${ }^{19,50}$ The elderly population becomes preponderantly female, with consequently greater demand for healthcare services, and this has already been described in Brazil. ${ }^{51}$

The clinical course of differentiated low back pain among women reveals that they are at a disadvantage in relation to disability. Our results indicated that the frequency of low back pain-related disability among women was higher, but there was in addition a significant difference in the associations for doctor visits and analgesic use, in relation to disability. This may lead to the idea that the greater longevity, higher prevalence of low back pain and differences in musculoskeletal constitution and activities of daily living among women may constitute the key reasons that would explain the higher prevalence of disability and use of medical services in this subgroup. ${ }^{1,652}$

It is an established practice for individuals with low back pain to be referred to healthcare services such as diagnostic imaging, rehabilitation and other therapies, after the first visit to a doctor. A study by primary care physicians in Germany showed that the decision to refer a patient to specialized care was influenced by the characteristics of the healthcare system and the low back pain-related disability. ${ }^{50}$ In Brazil, the decision to refer patients for subsequent care apparently is made if treatment guidelines are not followed. Thus, no associations between disability and imaging diagnoses, 
consultations with physiotherapists or use of other noninvasive therapeutic measures were found in the present study. Likewise, Jarvik et al. ${ }^{53}$ showed that performing imaging examinations (radiography, magnetic resonance or computed tomography) did not produce differing results regarding low back pain-related disability among American elderly people. Therefore, the results from this study are consistent with the recommendation that performing these tests does not justify conclusions that lead to unnecessary interventions and harmful exposures.

Among the indicators of use of healthcare services, physical therapy consultations offer the potential to explain the incapacity. However, in the present investigation, as corroborated through the investigations of Loy et al. ${ }^{54}$ and Freburger et al., ${ }^{55}$ there was no association between consultations with a physiotherapist and occurrences of low back pain-related disability. It is possible that this result was influenced by the low number of participants who had physical therapy consultation during the preceding six weeks (only $3 \%$ ), which would demonstrate flaws in the medical referral system within public services and health plan services in Brazil and problems regarding timely access. ${ }^{56}$ Therefore, it can be concluded that the structure and funding of the healthcare system may have influenced the low demand for physical therapy assistance observed here. Medical-centered healthcare and a model based on overmedicalization could also explain the low frequency of use of non-invasive therapies as an alternative for treating low back pain and the associated disability. ${ }^{13,14,17,56}$ This information can be used by health promoters, policymakers and urban planners to support effective policies, programs and initiatives to promote effective access and therapeutic interventions.

\section{Limitations}

The results from this study need to be considered cautiously. The cross-sectional design does not allow a temporal relationship to be established between the variables and the sample was predominantly composed of women, which may have led to underestimation of the results from the analyses between the subgroups. On the other hand, the present analysis was conducted on information that had been collected by trained professional interviewers using standardized instruments, which guaranteed the quality of the data. In addition, a careful analysis was carried out, considering potential confounding factors, according to the theoretical model. Thus, this study adds to the knowledge hitherto produced regarding the evidence from indicators of interventions associated with low back pain-related disability.

\section{CONCLUSIONS}

In summary, the present study demonstrated that the combined effect of consultations and medication use was associated with higher chances of low back pain-related severe disability among elderly people. This suggested that overuse of medical services and "crowding-in" effects at these services were occurring among elderly people. This knowledge can contribute towards enabling more thorough understanding of occurrences of this disease. This favors planning of actions aimed at individual and collective monitoring of the population that is most vulnerable to this outcome, at least with regard to the indicators for the use of healthcare services and therapeutic measures in this population segment.

\section{REFERENCES}

1. Romero DE, Santana D, Borges P, et al. Prevalence, associated factors, and limitations related to chronic back problems in adults and elderly in Brazil. Cad Saude Publica. 2018;34(2):e00012817. PMID: 29513823; http://doi.org/10.1590/0102-311×00012817.

2. Smith $E$, Hoy DG, Cross $M$, et al. The global burden of other musculoskeletal disorders: estimates from the Global Burden of Disease 2010 study. Ann Rheum Dis. 2014;73(8):1462-9. PMID: 24590181; http:// doi.org/10.1136/annrheumdis-2013-204680.

3. Hoy D, March L, Brooks $P$, et al. The global burden of low back pain: estimates from the Global Burden of Disease 2010 study. Ann Rheum Dis. 2014;73(6):968-74. PMID: 24665116; http://doi.org/10.1136/ annrheumdis-2013-204428.

4. Docking RE, Fleming J, Brayne C, et al. Epidemiology of back pain in older adults: prevalence and risk factors for back pain onset. Rheumatology (Oxford). 2011;50(9):1645-53. PMID: 21606130; http://doi.org/10.1093/ rheumatology/ker175

5. De Azevedo Barros MB, César CLG, Carandina L, Torre GD. Desigualdades sociais na prevalência de doenças crônicas no Brasil, PNAD-2003 [Social inequalities in the prevalence of chronic diseases in Brazil, PNAD-2003]. Cienc Saude Coletiva. 2006;11(4):911-26. http://doi.org/10.1590/S141381232006000400014.

6. Leopoldino AAO, Diz JBM, Martins VT, et al. Prevalência de lombalgia na população idosa brasileira: revisão sistemática com metanálise [Prevalence of low back pain in older Brazilians: a systematic review with meta-analysis]. Rev Bras Reumatol. 2016;56(3):258-69. http://doi. org/10.1016/j.rbr.2016.01.004

7. Eggermont LH, Leveille SG, Shi L, et al. Pain characteristics associated with the onset of disability in older adults: the maintenance of balance, independent living, intellect, and zest in the Elderly Boston Study. J Am Geriatr Soc. 2014;62(6):1007-16. PMID: 24823985; http://doi.org/10.1111/ jgs. 12848 .

8. Costa LCM, Maher CG, Hancock MJ, et al. The prognosis of acute and persistent low-back pain: a meta-analysis. CMAJ. 2012;184(11):E613-24. PMID: 22586331; http://doi.org/10.1503/cmaj.111271.

9. Rundell SD, Sherman KJ, Heagerty PJ, et al. Predictors of persistent disability and back pain in older adults with a new episode of care for back pain. Pain Med. 2017;18(6):1049-62. PMID: 27688311; http://doi. org/10.1093/pm/pnw236. 
10. Jarvik JG, Gold LS, Tan K, et al. Long-term outcomes of a large, prospective observational cohort of older adults with back pain. Spine J. 2018;18(9):154051. PMID: 29391206; http://doi.org/10.1016/j.spinee.2018.01.018.

11. Mafi JN, McCarthy EP, Davis RB, Landon BE. Worsening trends in the management and treatment of back pain. JAMA Intern Med. 2013;173(17):1573-81. PMID: 23896698; http://doi.org/10.1001/ jamainternmed.2013.8992.

12. Ferreira ML, Machado G, Latimer J, et al. Factors defining care-seeking in low back pain - A meta-analysis of population based surveys. Eur J Pain. 2010;14(7):e1-7.PMID:20036168; http://doi.org/10.1016/j.ejpain.2009.11.005.

13. Chou R, Deyo R, Friedly J, et al. Nonpharmacologic Therapies for Low Back Pain: A Systematic Review for an American College of Physicians Clinical Practice Guideline. Ann Intern Med. 2017;166(7):493-505. PMID: 28192793; http://doi.org/10.7326/M16-2459.

14. Chou R, Deyo R, Friedly J, et al. Systemic Pharmacologic Therapies for Low Back Pain: A Systematic Review for an American College of Physicians Clinical Practice Guideline. Ann Intern Med. 2017;166(7):480-92. PMID: 28192790; http://doi.org/10.7326/M16-2458.

15. Smith M, Davis MA, Stano M, Whedon JM. Aging baby boomers and the rising cost of chronic back pain: secular trend analysis of longitudinal Medical Expenditures Panel Survey data for years 2000 to 2007. J Manipulative Physiol Ther. 2013;36(1):2-11. PMID: 23380209; http:// doi.org/10.1016/j.jmpt.2012.12.001.

16. Pountos I, Panteli M, Walters G, Bush D, Giannoudis PV. Safety of Epidural Corticosteroid Injections. Drugs RD. 2016;16(1):19-34. PMID: 26715572; http://doi.org/10.1007/s40268-015-0119-3.

17. Gong $\mathrm{CH}$, Kendig $\mathrm{H}, \mathrm{He} X$. Factors predicting health services use among older people in China: an analysis of the China Health and Retirement Longitudinal Study 2013. BMC Health Serv Res. 2016;16:63. PMID: 26892677; http://doi.org/10.1186/s12913-016-1307-8.

18. Aguiar ARSA, Ribeiro-Samora GA, Pereira LSM, Godinho LB, Assis MG. Disability in older adults acute low back pain: the study Back Complaints in the Elderly - (Brazil). Braz J Phys Ther. 2017;21(5):365-71. PMID: 28941958; http://doi.org/10.1016/j.bjpt.2017.06.008.

19. Silva JP, Jesus-Moraleida F, Felício DC, et al. Biopsychosocial factors associated with disability in older adults with acute low back pain: BACEBrazil study. Cien Saude Colet. 2019;24(7):2679-90. PMID: 31340285; http://doi.org/10.1590/1413-8123201847.14172017.

20. Travassos C, Martins M. Uma revisão sobre os conceitos de acesso e utilização de serviços de saúde [A review of concepts in health services access and utilization]. Cad Saude Publica. 2004;20(2):S190-8. PMID: 15608933; http://doi.org/10.1590/S0102-311X2004000800014.

21. Andersen R, Newman JF. Societal and individual determinants of medical care utilization in the United States. Milbank Mem Fund Q Health Soc. 1973;51(1):95-124. PMID: 4198894.

22. Scheele J, Luijsterburg PA, Ferreira ML, et al. Back complaints in the elders (BACE); design of cohort studies in primary care: an international consortium. BMC Musculoskelet Disord. 2011;12:193. PMID:21854620; http://doi.org/10.1186/1471-2474-12-193.
23. Dionne CE, Dunn KM, Croft PR, et al. A consensus approach toward the standardization of back pain definitions for use in prevalence studies. Spine (Phila Pa 1976). 2008;33(1):95-103. PMID: 18165754; http://doi. org/10.1097/BRS.0b013e31815e7f94.

24. Koes B, Van Tulder M. Acute low back pain. Am Fam Physician. 2006;74(5):803-5. PMID: 16970025

25. Bertolucci PH, Brucki SM, Campacci SR, Juliano Y. O mini-exame do estado mental em uma população geral: impacto da escolaridade [The Mini-Mental State Examination in a general population: impact of educational status]. Arq Neuropsiquiatr. 1994;52(1):1-7. PMID: 8002795.

26. Roland M, Morris R. A study of the natural history of back pain. Part l: development of a reliable and sensitive measure of disability in lowback pain. Spine (Phila Pa 1976). 1983;8(2):141-4. PMID: 6222486; http:// doi.org/10.1097/00007632-198303000-00004.

27. Nusbaum L, Natour J, Ferraz MB, Goldenberg J. Translation, adaptation and validation of the Roland-Morris questionnaire - Brazil RolandMorris. Braz J Med Biol Res. 2001;34(2):203-10. PMID: 11175495; http:// doi.org/10.1590/s0100-879×20010002000007.

28. Szwarcwald CL, Damacena GN, Souza Júnior PRB, Almeida WS, Malta DC. Percepção da população brasileira sobre a assistência prestada pelo médico. Brasil, 2013. Cienc Saude Coletiva. 2016;21(2):339-50. http://doi.org/10.1590/1413-81232015212.19332015.

29. Traeger AC, Hübscher M, Henschke N, et al. Emotional distress drives health service overuse in patients with acute low back pain: a longitudinal observational study. Eur Spine J. 2016;25(9):2767-73. PMID: 26940056; http://doi.org/10.1007/s00586-016-4461-0.

30. Blay SL, Andreoli SB, Dewey ME, Gastal FL. Co-occurrence of chronic physical pain and psychiatric morbidity in a community sample of older people. Int J Geriatr Psychiatry. 2007;22(9):902-8. PMID: 17252525; http://doi.org/10.1002/gps.1761.

31. Hong JH, Kim HD, Shin HH, Huh B. Assessment of depression, anxiety, sleep disturbance, and quality of life in patients with chronic low back pain in Korea. Korean J Anesthesiol. 2014;66(6):444-50. PMID: 25006368; http://doi.org/10.4097/kjae.2014.66.6.444.

32. Bowen ME, González HM. Racial/ethnic differences in the relationship between the use of health care services and functional disability: the Health and Retirement Study (1992-2004). Gerontologist. 2008;48(5):659-67. PMID: 18981282; http://doi.org/10.1093/ geront/48.5.659.

33. Hestbaek L, Leboeuf-Yde C, Manniche C. Is low back pain part of a general health pattern or is it a separate and distinctive entity? A critical literature review of comorbidity with low back pain. J Manipulative Physiol Ther. 2003;26(4):243-52. PMID: 12750659; http://doi.org/10.1016/ s0161-4754(03)00003-4.

34. Pereira LV, Vasconcelos PP, Souza LA, et al. Prevalence and intensity of chronic pain and self-perceived health among elderly people: a population-based study. Rev Lat Am Enfermagem. 2014;22(4):662-9. PMID: 25296151; http://doi.org/10.1590/0104-1169-3591.2465. 
35. Stover BD, Turner JA, Franklin G, et al. Factors associated with early opioid prescription among workers with low back injuries. J Pain. 2006;7(10):718-25. PMID: 17018332; http://doi.org/10.1016/j. jpain.2006.03.004.

36. Ivanova Jl, Birnbaum HG, Schiller M, et al. Real-world practice patterns, health-care utilization, and costs in patients with low back pain: the long road to guideline-concordant care. Spine J. 2011;11(7):622-32. PMID: 21601533; http://doi.org/10.1016/j. spinee.2011.03.017.

37. Machado GC, Maher CG, Ferreira PH, et al. Efficacy and safety of paracetamol for spinal pain and osteoarthritis: systematic review and meta-analysis of randomized placebo controlled trials. BMJ. 2015;350:h1225. PMID: 25828856; http://doi.org/10.1136/bmj. h1225.

38. Wong JJ, Côté P, Ameis A, et al. Are non-steroidal anti-inflammatory drugs effective for the management of neck pain and associated disorders, whiplash-associated disorders, or non-specific low back pain? A systematic review of systematic reviews by the Ontario Protocol for Traffic Injury Management (OPTIMa) Collaboration. Eur Spine J. 2016;25(1):34-61. PMID: 25827308; http://doi.org/10.1007/s00586015-3891-4.

39. Takahashi N, Omata Jl, Iwabuchi M, Fukuda H, Shirado O. Therapeutic efficacy of nonsteroidal anti-inflammatory drug therapy versus exercise therapy in patients with chronic nonspecific low back pain: a prospective study. Fukushima J Med Sci. 2017;63(1):8-15. PMID: 28331155; http:// doi.org/10.5387/fms.2016-12.

40. Bohnert AS, Valenstein M, Bair MJ, et al. Association between opioid prescribing patterns and opioid overdose-related deaths. JAMA. 2011;305(13):1315-21. PMID: 21467284; http://doi.org/10.1001/ jama.2011.370.

41. Dowell D, Haegerich TM, Chou R. CDC Guideline for Prescribing Opioids for Chronic Pain - United States, 2016. MMWR Recomm Rep. 2016;65(1):149. PMID: 26987082; http://doi.org/10.15585/mmwr.rr6501e1.

42. Rolita L, Spegman A, Tang X, Cronstein BN. Greater number of narcotic analgesic prescriptions for osteoarthritis is associated with falls and fractures in elderly adults. J Am Geriatr Soc. 2013;61 (3): 335-40. PMID: 23452054; http://doi.org/10.1111/jgs.12148.

43. Ashworth J, Green DJ, Dunn KM, Jordan KP. Opioid use among low back pain patients in primary care: Is opioid prescription associated with disability at 6-month follow-up? Pain. 2013;154(7):1038-44. PMID: 23688575; http://doi.org/10.1016/j.pain.2013.03.011.

44. Solomon DH, Rassen JA, Glynn RJ, et al. The comparative safety of opioids for nonmalignant pain in older adults. Arch Intern Med. 2010;170(22):1979-86. PMID: 21149754; http://doi.org/10.1001/ archinternmed.2010.450.

45. Miller M, Stürmer T, Azrael D, Levin R, Solomon DH. Opioid analgesics and the risk of fractures in older adults with arthritis. J Am Geriatr Soc. 2011;59(3):430-8. PMID: 21391934; http://doi.org/10.1111/j.15315415.2011.03318.x.
46. Makris UE, Pugh MJ, Alvarez CA, et al. Exposure to high-risk medications is associated with worse outcomes in older veterans with chronic pain. Am J Med Sci. 2015;350(4):279-85. PMID: 26418380; http://doi. org/10.1097/MAJ.0000000000000552.

47. Nelson AD, Camilleri M. Opioid-induced constipation: advances and clinical guidance. Ther Adv Chronic Dis. 2016;7(2):121-34. PMID: 26977281; http://doi.org/10.1177/2040622315627801.

48. Gold LS, Hansen RN, Avins AL et al. Associations of early opioid use with patient-reported outcomes and healthcare utilization among older adults with low back pain. Clin J Pain. 2018;34(4):297-305. PMID: 28915153; http://doi.org/10.1097/AJP.0000000000000557.

49. Di Rosa M, Barbabella F, Chiatti C, Melchiorre MG, Lamura G. Private employment of home care workers and use of health services by disabled older people in Italy. Euroregional Journal of Socio-Economic Analysis. 2013;1 (1):33-42. Available from: https://www.researchgate. net/publication/258844272_Private_Employment_Of_Home_Care_ Workers_And_Use_Of_Health_Services_By_Disabled_Older_People_ In_Italy. Accessed in 2020 (Oct 30).

50. Chenot JF, Leonhardt C, Keller S, et al. The impact of specialist care for low back pain on health service utilization in primary care patients: a prospective cohort study. Eur J Pain. 2008;12(3):275-283. PMID: 17681811; http://doi.org/10.1016/j.ejpain.2007.06.004.

51. Instituto Brasileiro de Geografia e Estatística - IBGE. Síntese de Indicadores Sociais: uma análise das condições de vida da população brasileira. Rio de Janeiro (RJ); 2008.

52. Murtagh KN, Hubert HB. Gender differences in physical disability among an elderly cohort. Am J Public Health. 2004;94(8):1406-11. PMID: 15284051; http://doi.org/10.2105/ajph.94.8.1406.

53. Jarvik JG, Gold LS, Comstock BA, et al. Association of early imaging for back pain with clinical outcomes in older adults. JAMA. 2015;313(11):1143-53. PMID: 25781443; http://doi.org/10.1001/jama.2015.1871.

54. Loy FL, Yang SY, Chemat J, Tjan SY. Health professionals'referral practice and related healthcare utilization for people with low back pain in Singapore: a retrospective study. Hong Kong Physiother J. 2019;39(1):114. PMID: 31156313; http://doi.org/10.1142/S101370251950001X.

55. Freburger JK, Carey TS, Holmes GM. Physician referrals to physical therapists for the treatment of spine disorders. Spine J. 2005;5(5):53041. PMID: 16153582; http://doi.org/10.1016/j.spinee.2005.03.008.

56. da Silva ZP, Ribeiro MC, Barata RB, de Almeida MF.Perfil sociodemográfico e padrão de utilização dos serviços de saúde do Sistema Único de Saúde (SUS), 2003-2008 [Socio-demographic profile and utilization patterns of the public healthcare system (SUS), 2003-2008]. Cienc Saude Colet. 2011;16(9):3807-16. PMID: 21987323; http://doi.org/10.1590/ s1413-81232011001000016.

Authors' contributions: Amorim JSC: conceptualization (equal), data curation (equal), formal analysis (equal), investigation (equal), methodology (equal), writing-original draft (equal) and writing-review and editing (equal); Rocha VTM: conceptualization (equal), investigation 
(equal), methodology (equal), supervision (equal), validation (equal) and writing-review and editing (equal); Lustosa LP: conceptualization (equal), methodology (equal) and writing-review and editing (equal); and Pereira LSM: conceptualization (equal), data curation (equal), funding acquisition (equal), methodology (equal), project administration (equal) and supervision (equal). All authors approved the final version of the article and assume public responsibility for its content

Sources of funding: This work was supported by the Conselho Nacional de Desenvolvimento Científico e Tecnológico (CNPq), through grant number 471264/2010-5

Conflicts of interest: The authors do not have any conflicts of interest to declare and this study has not been published previously

Date of first submission: October 30, 2020

Last received: December 3, 2020

Accepted: December 7, 2020

\section{Address for correspondence:}

Juleimar Soares Coelho de Amorim

Curso de Fisioterapia, Physical Therapy Course, Instituto Federal de

Educação Ciência e Tecnologia do Rio de Janeiro (IFRJ), Campus Realengo

R. Professor Carlos Wenceslau, 343,

Realengo — Rio de Janeiro (RJ) — Brasil

CEP 21710-240

Tel. (+55 21) 3107-6013

E-mail: juleimar@yahoo.com.br 